\title{
Association Between Economic Inequality and Under-Five Child Malnutrition: Evidence from Bangladesh Demographic and Health Survey
}

\author{
A H M Musfiqur Rahman Nabeen ${ }^{1}$ and Md. Abdus Salam Akanda ${ }^{2 *}$ \\ ${ }^{1}$ Department of Statistics, Pabna University of Science and Technology, Pabna 6600, Bangladesh \\ ${ }^{2}$ Department of Statistics, Dhaka University, Dhaka- 1000, Bangladesh
}

( Received: 9 November 2017 ; Accepted :17 December 2017)

\begin{abstract}
Under-five child malnutrition is an important phenomenon in developing countries like Bangladesh. Historically certain privileged groups have been benefited by the improvements in economic conditions inflicting health care inequality among the population. This study attempts to examine the association between economic inequality of households and adverse under-five child malnutrition using information from 4,976 children aged 0 to 59 months of Bangladesh Demographic and Health Survey, 2014 data. A child is said to be an adversely malnourished if the growth rate is badly stunted i.e., if z-score of the measure height-for-age of a child is more than the two standard deviations under the median. Multivariate logistic regression is used to estimate the household's economic effect on the rate of adverse growth-stunting of children. The estimation results show that children from the poorest group are about four times more likely to experience malnutrition than the children from the richest group ( $\mathrm{OR}=4.32 ; 95 \% \mathrm{CI}: 3.83,5.07)$. The effects of economic status on childhood under-nutrition are also significant when the analysis is adjusted for child's age, gender, multiple birth status, antenatal care, skilled birth assistance, birth order number ( $\mathrm{OR}=3.43$; 95\% CI: 3.04, 3.87); mother's BMI, mother's education level (OR=3.05; 95\% CI: $2.71,3.48)$; residence type, and geographic region $(\mathrm{OR}=3.14 ; 95 \% \mathrm{CI}: 2.74,3.63)$. Hence, this study suggests that there is a statistically significant association between the household economic inequality and the growth rate stunting of children. Reduction of poverty and making social security services as well as maternal medical supports more available to the poor people are necessary to improve the overall under-five childhood malnutrition condition in Bangladesh.
\end{abstract}

Keywords: Economic inequality, Malnutrition, Growth-rate stunting, Odds ratio, Bangladesh.

\section{Introduction}

Under-five child malnutrition is one of the indicators that assesses the overall health status of the children of a country and it is interconnected with poverty. There is a significant improvement in under-five child mortality, malnutrition and poverty condition in many developing countries over the last decades ${ }^{1-2}$. In spite of these remarkable advancements, still many people are defenseless to under-nutrition, ill health, lack of food security etc ${ }^{3}$. These types of problems are serious especially in developing countries like Bangladesh which are struggling to escape the curse of extreme poverty. This may be due to the fact that the public health and nutritional advancements originated from economic growth is only focused among the certain privileged groups of the countries $^{4-5}$.

Malnutrition is one of the major causes of child mortality and morbidity in Bangladesh ${ }^{6-7}$. The combined effects of lack of sufficient food, repetitive incidents of infections and lack of adequate care at the period of sickness often cause malnutrition among children. Furthermore, malnutrition upsets physical growth, debilitates the internal immune system and enhances the risks of infections ${ }^{8}$. World Health Organization (WHO) identified malnutrition as leading cause of disease ${ }^{9}$. A number of research studies provide evidence that there is an association between under-five child malnutrition with child's gender, age, multiple-birth status, birth interval, mother's education and BMI, parent's health care seeking behavior like taking antenatal care and expert birth assistance at the time of delivery, rural residence, race or ethnicity, geographic division etc ${ }^{10-13}$.

It is perceived that the countries with lack of economic equality have a tendency to have a poorer health status than the countries that have more economic equality ${ }^{2,14}$. Larger national affluence does not certainly ensure the better health care for the entire citizens. Hence maximization of financial growth should not the best method of advancing overall health care condition ${ }^{15}$. Previous research studies have demonstrated that the poorest household children have more chance to be undernourished than the richer household children ${ }^{13,16-18}$. But there is no conclusive association between child's malnutrition and household economic inequality yet. Hence, the main objective of this study is to examine the association between childhood malnutrition and household economic inequality. It also examine the effects of different other confounding risks factors on under-five childhood malnutrition.

\section{Materials and Methods}

Bangladesh Demographic and Health Survey (BDHS), 2014 data ${ }^{19}$ are utilized for this study. The survey was conducted by National Institute of Population Research and Training (NIPORT) of the Ministry of Health and Family Welfare (MHFW) in Bangladesh. A research firm of Bangladesh located in Dhaka named Mitra and Associates implemented the overall survey and technical support was provided through the MEASURE DHS program by Macro International Inc., a private research firm located in Calverton, Maryland, USA. The U.S. Agency for International Development (USAID) provided financial support for the survey. Bangladesh was stratified into 20 strata where each stratum is considered as enumeration areas (EAs) while conducting the survey. A two-stage stratified random sampling procedure was followed. At the first stage of sampling, the survey randomly selected 600 EAs (among them 393 in rural areas and 207 in urban areas) applying probability proportional to the EA size. A systematic random sample of 30 households was selected on average from each EA in the second stage of sampling. Finally, the information

"Author for correspondence. e-mail: akanda@ du.ac.bd 
of 17,863 ever-married women aged 12 to 49 year were collected from the selected households. The BDHS, 2014 also collected demographic, socioeconomic, and healthrelated information for the finally selected ever-married women. The main BDHS report provides details of the sampling design ${ }^{20}$. The analysis of this study is used information of 4,976 children with legal information on height or length. The children whose information was in valid or missing were excluded.

The survey used height or length of all 0-59 months' children to measure the nutritional status and physical growth of children. Three typical indices that define child's nutritional status are wasting (weight-for-height), underweight (weight-for-age) and stunting (height-for-age). However, only stunting is considered as an index of nutritional status of children in this study as it reveals the cumulative effect of enduring malnutrition and it does not fluctuate substantially on the basis of current dietary intake. World Health Organization (WHO) considered children as growth-stunted or under-nourished establishing a children's z-score measure (height-for-age) above two standard deviations less than the international standard of median ${ }^{21}$.

Using principle component analysis, BDHS also measures wealth status of households which is evaluated from some asset variables and household characteristics ${ }^{22}$. The characteristics used to assess the household wealth status take account of having sanitation facility, electricity, safe drinking water, main wall material, roof material, floor material etc. The asset variables contain land ownership and different durable goods like wardrobe, watch or clock, chair, radio, bench, television, computer, bicycle, motorcycle, table, telephone, sewing machine etc $^{20}$. In this current analysis this wealth index measure is considered as a substitution for economic status of households. Household economic inequality is calculated by separating this wealth index into five quintiles. The lowermost quintile presents the poorest $20 \%$ and the uppermost quintile presents the wealthiest 20\% households in Bangladesh.

Economic status is associated with other demographic and socioeconomic factors which are also responsible to influence the nutrition of children. Hence the analysis of this study is adjusted for other possibly confounding factors. Those confounding factors are: multiple birth status (single, multiple), age of the child $(0-11,12-23,24-35,36-47,48-$ 59 months), gender (boy, girl), taking antenatal care (no, yes), availability of skilled birth attendant (no, yes), birth order number $(1,2,3,4+)$; mother's BMI index $(\mathrm{kg} / \mathrm{m} 2)$ (less than $18.5,18.5$ to 24.9 , more than 25.0 ), maternal education level (no education, primary, secondary or higher); residence type (rural, urban) and geographical region (Barisal, Sylhet, Rangpur, Rajshahi, Khulna, Dhaka, Chittagong).

The effects of economic status and confounding factors on childhood malnutrition are estimated using multivariate logistic regression framework. The results of this study are represented as percentage of stunting with level of significance (p-value) in univariate and bivariate analysis, and odds ratio with $95 \%$ confidence interval in multivariate analysis.

\section{Estimation Results}

The percentage distribution of the covariates and the rate of the prevalence of stunting are shown in Table 1. It is observed that about $22 \%$ children are from richest family, $19 \%$ from both rich and middle class family, $21 \%$ from poor family whereas $17 \%$ from poorest family. Marginally $1 \%$ of the children are multiple births and others are single birth. The distributions of the children are almost equal with respect to gender and age categories. About $40 \%$ mothers are able to receive antenatal care while $36 \%$ of them are capable to manage as killed birth attendant. Approximately $38 \%, 26 \%, 20 \%$ and $14 \%$ children are born as first order, second order, third order and other order birth respectively. Around 55\% mothers have a normal body mass index whereas $36 \%$ and $8 \%$ are underweight and overweight respectively. In case of education about $15 \%$ of mothers do not have any formal education while $31 \%$ have primary and $53 \%$ have secondary or higher education. Most of the children live in rural area (68\%) and other $32 \%$ children live in urban area. According to geographic region, about $19.90 \%$ of the children reside in the Chittagong division, about $16 \%$ in the Dhaka and Sylhet divisions, $11 \%$ in the Khulna and Barisal divisions and about $12 \%$ of them live in the Rajshahi and Rangpur division.

About 36\% under-five children are the sufferer of adverse growth-rate stunting in Bangladesh (Table 1). The prevalence rate of under-five childhood adverse growthstunting decreases as the household economic status rises. The prevalence of stunting is about $47 \%$ in the poorest households, $43 \%$ in poor households, $41 \%$ in middle class households, $35 \%$ in rich households and only $18 \%$ in richest households. The prevalence rate of chronic growth-stunting increases with the increase of child age and it is higher among the children of multiple births. The prevalence of stunting quickly rises between 12 to 23 months of age, after then it doesn't fluctuate significantly. One cause behind the low prevalence of stunting at the 0-11 months age group may be that within these months most of the babies are breastfed. The rate does not vary considerably by the gender of child. However, it is greater among the children whose mothers do not take antenatal care and give birth of their children without the presence of a skilled birth attendant. The rate is slightly higher among the children of fourth or higher order births. There is a significant negative relationship between the prevalence of stunting and mother's BMI, and mother's education level. If the maternal education level increases then the prevalence rate of growthstunting will decrease. It is less in urban areas (32\%) compared to the rural areas (38\%). According to geographic location the stunting rate is higher at Barisal division (45\%) and lowest at Khulna division (30\%). 
Table 1. Summary statistics of the covariates and prevalence of stunting by economic status and other selected covariates

\begin{tabular}{|c|c|c|c|c|}
\hline Characteristic & Frequency & Percentage & Prevalence rate of stunting (\%) & p-value \\
\hline Bangladesh & 4976 & & 36.76 & \\
\hline $\begin{array}{l}\text { Economic status } \\
\text { Richest } \\
\text { Rich } \\
\text { Middle } \\
\text { Poor } \\
\text { Poorest }\end{array}$ & $\begin{array}{c}1114 \\
952 \\
938 \\
1086 \\
866\end{array}$ & $\begin{array}{l}22.39 \\
19.15 \\
19.27 \\
21.83 \\
17.41\end{array}$ & $\begin{array}{l}18.14 \\
35.96 \\
41.51 \\
43.00 \\
47.05\end{array}$ & 0.001 \\
\hline $\begin{array}{l}\text { Multiple birth status } \\
\text { Single } \\
\text { Multiple }\end{array}$ & $\begin{array}{c}4922 \\
54 \\
\end{array}$ & $\begin{array}{c}98.92 \\
1.08 \\
\end{array}$ & $\begin{array}{l}36.08 \\
64.21 \\
\end{array}$ & 0.001 \\
\hline $\begin{array}{l}\text { Age of the child (months) } \\
0-11 \\
12-23 \\
24-35 \\
36-47 \\
48-59\end{array}$ & $\begin{array}{c}1022 \\
1063 \\
988 \\
915 \\
989\end{array}$ & $\begin{array}{l}20.55 \\
21.35 \\
19.86 \\
18.38 \\
19.87\end{array}$ & $\begin{array}{l}17.38 \\
40.90 \\
42.79 \\
43.56 \\
42.76\end{array}$ & 0.001 \\
\hline $\begin{array}{l}\text { Child's gender } \\
\text { Male } \\
\text { female }\end{array}$ & $\begin{array}{l}2518 \\
2458 \\
\end{array}$ & $\begin{array}{l}50.62 \\
49.38\end{array}$ & $\begin{array}{l}36.89 \\
37.96 \\
\end{array}$ & 0.231 \\
\hline $\begin{array}{l}\text { Antenatal Care } \\
\text { No } \\
\text { Yes }\end{array}$ & $\begin{array}{l}2971 \\
2005 \\
\end{array}$ & $\begin{array}{l}59.71 \\
40.29 \\
\end{array}$ & $\begin{array}{l}43.67 \\
26.44 \\
\end{array}$ & 0.002 \\
\hline $\begin{array}{l}\text { Skilled birth attendant } \\
\text { No } \\
\text { Yes }\end{array}$ & $\begin{array}{l}3160 \\
1816 \\
\end{array}$ & $\begin{array}{l}63.50 \\
36.50 \\
\end{array}$ & $\begin{array}{l}44.78 \\
23.34 \\
\end{array}$ & 0.001 \\
\hline $\begin{array}{l}\text { Birth order number } \\
1^{\text {st }} \\
2^{\text {nd }} \\
3^{\text {rd }} \\
\text { Other }\end{array}$ & $\begin{array}{c}1325 \\
1331 \\
1023 \\
697 \\
\end{array}$ & $\begin{array}{l}38.69 \\
26.75 \\
20.56 \\
14.00\end{array}$ & $\begin{array}{l}36.23 \\
34.56 \\
37.89 \\
40.56\end{array}$ & 0.001 \\
\hline $\begin{array}{l}\text { Mother's BMI index }(\mathbf{k g} / \mathbf{m} 2) \\
\text { Less than } 18.5 \\
18.5 \text { to } 24.9 \\
\text { More than } 24.9 \\
\end{array}$ & $\begin{array}{c}1808 \\
2750 \\
418\end{array}$ & $\begin{array}{c}36.33 \\
55.27 \\
8.40 \\
\end{array}$ & $\begin{array}{l}43.65 \\
34.97 \\
16.75 \\
\end{array}$ & 0.001 \\
\hline $\begin{array}{l}\text { Maternal education } \\
\text { No education } \\
\text { Primary } \\
\text { Secondary or higher }\end{array}$ & $\begin{array}{c}761 \\
1563 \\
2652\end{array}$ & $\begin{array}{l}15.30 \\
31.40 \\
53.30\end{array}$ & $\begin{array}{l}48.78 \\
39.43 \\
30.45\end{array}$ & 0.001 \\
\hline $\begin{array}{l}\text { Residence type } \\
\text { Urban } \\
\text { Rural }\end{array}$ & $\begin{array}{l}1597 \\
3379 \\
\end{array}$ & $\begin{array}{l}32.10 \\
67.90 \\
\end{array}$ & $\begin{array}{l}30.45 \\
39.67 \\
\end{array}$ & 0.001 \\
\hline $\begin{array}{l}\text { Geographic location } \\
\text { Barisal } \\
\text { Sylhet } \\
\text { Rangpur } \\
\text { Rajshahi } \\
\text { Khulna } \\
\text { Dhaka } \\
\text { Chittagong }\end{array}$ & $\begin{array}{l}553 \\
802 \\
632 \\
617 \\
558 \\
822 \\
992 \\
\end{array}$ & $\begin{array}{l}11.12 \\
16.10 \\
12.70 \\
12.39 \\
11.20 \\
16.51 \\
19.90 \\
\end{array}$ & $\begin{array}{l}44.78 \\
31.56 \\
37.12 \\
32.67 \\
29.23 \\
39.56 \\
40.76 \\
\end{array}$ & 0.001 \\
\hline
\end{tabular}

Association between economic status and adverse under-five childhood growth-stunting

The adjusted and unadjusted effects of economic status on adverse stunting are presented in Table 2. In Model 1 without controlling the other risk factors, the odds of having chronic growth-stunting are 4.32 times higher among the children who are living in the poorest houses than the children who are living in the richest houses $(\mathrm{OR}=4.32$; 
95\% CI: 3.83, 5.07). If economic status of a household increases then the odds of having childhood growth-stunting decreases. This association remains strong enough even when multiple birth-status of child, gender, age, antenatal care, the presence of skilled birth attendants and birth order number are controlled in Model 2 (OR=3.43; 95\% CI: 3.04, 3.87). When these characteristics of children are controlled for the odds of experiencing adverse growth-stunting are about three and a half times higher in the poorest households compared to the richest households. On the other hand when mother's characteristics such as education level and BMI index are controlled in Model 3 the effect of economic status slightly reduces $(\mathrm{OR}=3.05 ; 95 \% \mathrm{CI}: 2.71,3.48)$. In the complete model, when all the child's, maternal and other characteristics are controlled, the effect of household economic status on adverse growth-stunting of under-five children remains statistically significant $(\mathrm{OR}=3.14 ; 95 \%$ CI: $2.74,3.63)$.

Table 2. Estimated effects of economic status and different other selected covariates on adverse under-five childhood growth-stunting

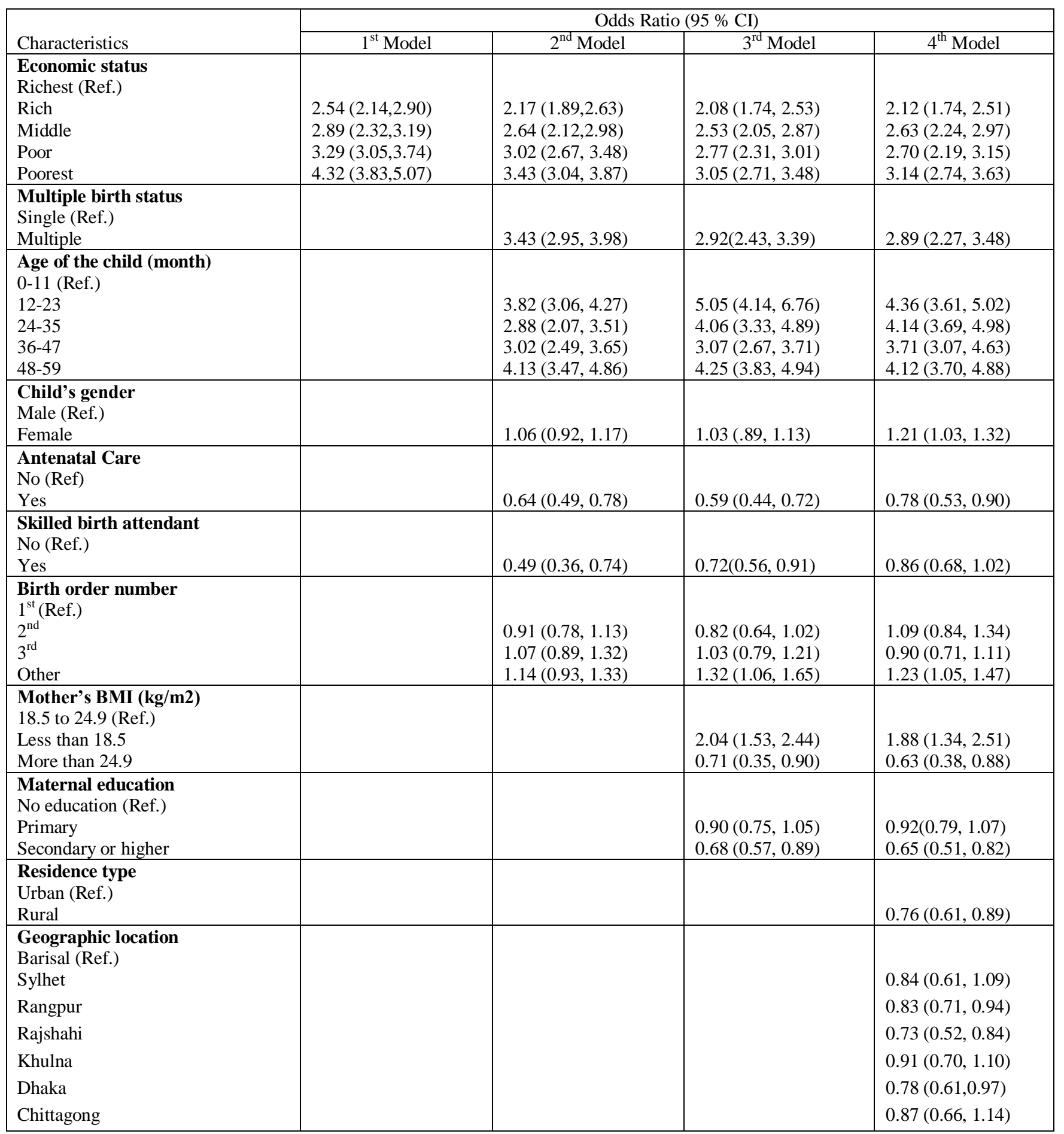




\section{Discussion and Conclusion}

The under-five child malnutrition is a susceptible indicator of the overall nutrition and health condition of a country. It is a development indicator as it measures the standard of life and it portrays the strength of development all together governed by low socio-economic status and poverty ${ }^{23}$. It is essential to study malnutrition on a continuous basis since it replicates the cumulative result of health, socio-economic and nutritional shortcomings and which may change over time.

The results of this study indicate that children within wealthier households are at a very lower threat of being malnourished compared to the children within less wealthy households. Children from the poorest families are at over four times the chance of being suffered from severe growth rate stunting of under-five children than the children of the richest households. The result does not dependent on child's age, sex, birth status, birth order number, receiving antenatal care, mother's education and BMI and other vital factors. These findings agree with the findings from previous research ${ }^{4,17,6,12}$ and give further indication that household economic inequality is a potential risk factor for chronic under-five childhood malnutrition.

There is no significant difference in adverse growth-stunting between male and female which illustrates the absence of gender bias in health-related care and feeding for under-five children in Bangladesh. An upward pattern of growth rate stunting by age categories is similar with the usual upward pattern of occurrence of under-five childhood diseases with the increase of age ${ }^{18}$. This may partially be as a result of the starting of feeding outside foods around the age of 6 months, which enhances the probability of consuming unhygienic foods and eliminates the natural protection of child provided by mother's breast milk. Besides, at this age children start wandering outside and are more chance to be carried outer that may harm them to further diseases. Consistent with earlier research study, children of single-births have more chance to be nourished than the children of multiple births ${ }^{24}$. The relationship between higher-order births and adverse growth rate stunting may be because of the struggles for food existing within a household which is more likely in those households where more number of children is present and it is analogous to earlier findings ${ }^{6}$. Mother's education level which can also influence household income is described as one of the key factors for influencing a family's health and nutritional status in many previous studies ${ }^{7,13}$. This study also gets the similar result.

There is a potential limitation of using cross sectional design in this study. Besides, this study may be denounced for not applying direct measure of household economic asset. However, it is difficult to collect dependable household income and expenditure data in developing countries like Bangladesh. Hence in this study an asset-based measure is used a best proxy for household economic status. Apart from these limitations, this study demonstrates that there is a statistically significant between economic status and underfive childhood growth-stunting and others important factors.
Thus it suggests that the improvement of malnutrition condition of the under-five children in Bangladesh may be achieved through integrating and expanding extensive nutritional programs and community health targeting the poor.

The results of this research reveal that there are wide scopes for increasing child nutrition in Bangladesh. To reduce the risk of malnutrition among children, it is absolutely essential a combined efforts of government and non-governmental institutions to improve the child nutritional status. Besides the ongoing programs for child health development, the government may conduct some targeted nutrition strategies to improve nutritional status. Moreover, government may take necessary steps to substantiate the easier access to health information centers and special care should be given to helpless poorest people of the society. Healthy mothers are capable to give births of healthy children. Thus for the purpose of promoting the child nutritional status, the concentration of interventional programs should be provided to the children and their mothers together. The authors intend to recommend that health and nutrition education need to be integrated as a basic part of the whole education system.

\section{Acknowledgement}

We are greatly indebted to the NIPORT, Bangladesh for the BDHS, 2014 survey data.

\section{References}

1. United Nation Development Programme, 2016. Human development report 2016. New York: UNDP.

2. World Bank, 2016. World development report 2016. Washington, DC: World Bank.

3. Asian Development Bank, 2017. Bangladesh development effectiveness country brief, $A D B$.

4. Rathavuth, H., J.E. Banta and J.A. Betancourt, 2006. Relationship between household wealth inequality and chronic childhood under-nutrition in Bangladesh. International Journal for Equity in Health, 5, 15.

5. Thang, N.M. and B.M. Popkin, 2003. In an era of economic growth, is inequity holding back reduction in child malnutrition in Vietnam? Asia Pacific Journal of Clinical Nutrition, 12, 405-10.

6. Rahman, M, 2016. Association between order of birth and chronic malnutrition of children: a study of nationally representative Bangladeshi sample. Cad. Saúde Publica, Rio de Janeiro, 32(2), 1-12.

7. Mohammad, K.A., M.E. Haque, W. Bari, 2017. Does community facility play a vital role on nutrition status of under-five children in Bangladesh? Dhaka University Journal of Science, $\mathbf{6 5}(\mathbf{1})$ 27-33.

8. WHO, 2010. Child mortality levels: Probability of dying per 1000 live births data by county. World Health Organisation.

9. World Health Statistics, 2016. World Health Organization, Geneva.

10. Jacobs, B. and E. Robert, 2004. Baseline assessment for addressing acute malnutrition by public health staff in Cambodia. Journal of Health Population and Nutrition, 22, 212-9. 
11. Reyes, H., R. Perez-Cuevas, A. Sandoval, R. Castillo, J.I. Santos, S. Doubova and G. Gutierrez, 2004. The family as a determinant of stunting in children living in conditions of extreme poverty: A case-control study. BMC Public Health, $4,57$.

12. Jesmin, A, S. S. Yamamoto, A, A Malik, and A Haque, 2011. Prevalence and determinants of chronic malnutrition among preschool children: a cross-sectional study in Dhaka city, Bangladesh. J Health Popul. Nutr, 29(5): 494-499.

13. Zewdie, T., \& D. Abebaw, 2013. Determinants of child malnutrition: empirical evidence from Kombolcha District of Eastern Hararghe Zone, Ethiopia. Quarterly Journal of International Agriculture, 52(4), 357-372.

14. Ross, N.A., M.C. Wolfson, J.R. Dunn, J. Berthelot, G.A. Kaplan and J.W. Lynch, 2000. Relation between income inequality and mortality in Canada and in the United States: Cross sectional assessment using census data and vital statistics. British Medical Journal, 320, 898-902.

15. Wilkinson, R.G., 1999. Putting the picture together: Prosperity, redistribution, health, and welfare. Social Determinants of Health. 2, 256-74.

16. Larrea, C. and W. Freire, 2002. Social inequality and child malnutrition in four Aden countries. Revista Panamericana de Salud Publica, 11, 356-64.

17. Wang, Y., C. Monteiro and B.M. Popkin, 2002. Trend of obesity and underweight in older children and adolescence in the United States, Brazil, China, and Russia. American Journal of Clinical Nutrition. 75, 971-7.
18. Das S., RM Rahman, 2011. Application of ordinal logistic regression analysis in determining risk factors of child malnutrition in Bangladesh. Nutrition Journal, 10, 124.

19. BDHS (2014). Bangladesh demographic and health survey. Niport, Dhaka, Bangladesh; Mitra and Associates, Dhaka, Bangladesh.

20. BDHS (2014). Bangladesh demographic and health survey report. Niport, Dhaka, Bangladesh; Mitra and Associates, Dhaka, Bangladesh.

21. Dibley, M.J., N.W. Staehling, P. Neiburg and F.L. Trowbridge, 1987. Interpretation of z-score anthropometric indicators derived from the international growth reference. American Journal of Clinical Nutrition, 46, 749-762.

22. Rutstein S.O. and K. Johnson, 2004. DHS Comparative report No. 6: The DHS wealth index Calverton MD, ORC Macro.

23. Demissie S., A. Worku, 2013. Magnitude and factors associated with malnutrition in children 6-59 months of Age in pastoral community of dollo Ado district, Somali region, Ethiopia. Scientific Journal of Public Health, 1(4), 175-83.

24. Jaffar, S., A. Jepson, A. Leach, A. Greenwood, H. Whittle and B. Greenwood, 1998. Causes of mortality in twins in a rural region of the Gambia, West Africa. Annals of Tropical Paediatrics, 18, 231-8. 